\title{
ADHERENCE TO COVID-19 MITIGATION MEASURES: THE ROLE OF SOCIODEMOGRAPHIC AND PERSONALITY FACTORS
}

Eva Turk ${ }^{1 *}$, Tatjana Čelik ${ }^{1 *}$, Maja Smrdu ${ }^{2}$, Janko Šet ${ }^{1}$, Ana Kuder ${ }^{2}$, Matjaž Gregorič ${ }^{1}$, Simona Kralj-Fišer ${ }^{1,2, * *}$

*shared first authorship (equal contribution)

${ }^{1}$ Jovan Hadži Institute of Biology, Research Centre of the Slovenian Academy of Sciences and Arts, Ljubljana, Slovenia

${ }^{2}$ Department of Psychology, The Faculty of Mathematics, Natural Sciences and Information Technologies, University of Primorska, Koper, Slovenia

**Corresponding author: Jovan Hadži Institute of Biology, ZRC SAZU, Novi trg 2, SI-1000 Ljubljana, phone: +38614706333, e-mail: simona.kralj-fiser@zrc-sazu.si

\section{AKNOWLEDGEMENTS}

We thank Tjaša Lokovšek and Rok Golobinek for their help with ideas and the questionnaire. This work was funded by the Slovenian Research Agency grant P1-0236. 


\begin{abstract}
Objective: To investigate the perception and adherence to mitigation measures during the first wave of the COVID-19 epidemic in Slovenia by examining their trends across several sociodemographic categories and personality dimensions. Methods: Descriptive and correlative analyses were used to examine which sociodemographic and personality factors were associated with participants' attitudes and adherence to measures. Results: More than $90 \%$ of participants considered the following four measures as important and practiced them always/often: keeping a safe interpersonal distance, regular and thorough hand washing/disinfection, adherence to the rules of cough hygiene, and regular indoor ventilation. The strongest predictors of confidence in the preventive measures and their implementation were the participants' concern of infection and concern of infecting their loved ones, followed by gender (with higher measure adherence in women) and age (with higher measure adherence in participants under 30 and over 60 years of age). Education, settlement size, field and type of employment, household type, own medical problems, and the age and health of the participants' loved ones had a smaller influence on the perceived importance and implementation of guidelines. Adherence to measures was positively related to the participants' score in conscientiousness and, in lesser extent, openness. Agreeableness, energy, and emotional stability correlated positively with adherence to basic guidelines. Conclusions: Study provides information useful for developing and adapting future public health policies and interventions in Slovenia.
\end{abstract}

Key words: COVID-19; guidelines adherence; sociodemographic factors; personality; gender, conscientiousness 


\section{Introduction}

The global COVID-19 pandemic and associated measures to prevent its spread were and remain a burden to public health and the economic, political, and social stability around the world. The Slovenian government first declared the epidemic on 12 March 2020 and issued a series of strictly enforced mitigation measures as well as several voluntary guidelines. Like elsewhere, the main mitigation measures included the prohibition of gathering outside one's household, closure of all non-essential stores and services, closure of educational institutions, and limitation of movement within the country. Strict COVID-19 mitigation measures suddenly put the entire population into an unfamiliar situation, drastically altering the everyday life of people. The first main aim was to explore the perception of mitigation measures during the first wave of the epidemic. Specifically, it was examined how people perceived the importance of measures and guidelines, and to what extent these were abided to and how their abidance differed across several sociodemographic categories.

Similar studies related to the COVID-19 pandemic have been conducted in several countries. For example, in Italy, there was overwhelming support and adherence to public health measures during the first wave of the pandemic across all age groups, genders and health status, with few exceptions. Young adults adhered to social distancing and hand washing less, while people of low income were notably less compliant with staying at home (Barari et al., 2020). Similar trends were recovered in the UK, where most respondents abided to at least one preventive measure, with higher rates among people aged over 70 years (Atchison et al., 2020). Those with the lowest household income were able to work from home and isolate from others less frequently, although their willingness to do so was as high as in other groups (Atchison et al., 2020). During the first pandemic wave in France, there was a positive association between age and measure compliance. Also, women were more likely to adjust their behavior according to public health measures, while education had no effect (Brouard, Vasilopoulos, \& Becher, 2020).

In the USA, compliance with health promoting guidelines was generally high (Park et al., 2020; van Rooij et al., 2020). There was overwhelming adherence to social distancing and appropriate hygiene, while age, gender and financial security were the most consistent sociodemographic predictors of adherence (Park et al., 2020). Furthermore, a large international study found women slightly more likely to adhere to mitigation measures, take health precautions, and make health recommendations to others. However, the same study found no relationship between age and measure adherence, and only a weak relationship between age and health precaution implementation, suggesting vulnerability to COVID-19 might not be a reliable predictor of rule compliance and health promoting behavior (Clark et al., 2020).

The second main aim was to test whether adherence to guidelines correlated to peoples' personality traits. Personality is one's unique and relatively stable pattern of behavior, thoughts, and emotions (McCrae \& Costa, 2006), all of which affect one's lifestyle, including health promoting (healthy diet, exercise, preventive health screening) and health risk (dangerous driving, drug abuse, alcohol consumption) behaviors and actions. Thus, personality traits may influence how people 
perceive, cope and behave during pandemics. The present study aimed to examine how five personality dimensions - conscientiousness, neuroticism, extraversion, openness, and agreeableness - contributed to people's adherence to restrictions, measures and guidelines intended to limit the spread of COVID19 during the first pandemic wave.

Individuals scoring high in conscientiousness tend to follow norms and rules, are goal-oriented and show good impulse control (Bogg \& Roberts, 2004). They tend to refrain from risky behaviors (smoking, excessive drinking, dangerous driving, unhealthy diet), practice a healthy lifestyle and follow doctors' instructions (Aschwanden et al., 2019; Bogg \& Roberts, 2004; Friedman et al., 1995; Molloy, O'Carroll, \& Ferguson, 2014; Sutin et al., 2016). Expectedly, conscientiousness proved to be the key predictor of adherence to COVID-19 mitigation measures in existing studies (Abdelrahman, 2020; Aschwanden et al., 2020; Blagov, 2020, Carvalho, Pianowski, \& Gonçalves, 2020; Clark et al., 2020; Stadler et al., 2020).

People scoring high in neuroticism tend to be more sensitive to threat and frustration, and can be prone to health risk behaviors, such as alcohol consumption, smoking, drug abuse, sedentary lifestyle, and unhealthy diet (Gale et al., 2017; Hakulinen et al., 2015; Mroczek, Spiro, \& Turiano, 2009; Sutin et al., 2016; Vollrath \& Torgersen, 2002). Conversely, they tend to worry about health risks (Costa \& McCrae, 1985) and practice health promoting behaviors, e.g., attentiveness to bodily changes, employing preventive health screenings and seeking medical attention when needed (Aschwanden et al., 2019; Weston \& Jackson, 2018). In relation to COVID-19, existing studies report mixed evidence on the relationship between neuroticism and avoidance of health risk behaviors (Abdelrahman, 2020; Aschwanden et al., 2020; Blagov, 2020; Bogg \& Milad, 2020; Clark et al., 2020; Stadler et al., 2020).

Extraversion is manifested in assertive, talkative, energetic behavior and seeking of social interactions, while introversion reflects in reserved or reflective behaviors and engagement in solitary activities. There is ambiguous support for the relationship between extraversion and health risk and health promoting behaviors. For example, extraverts may be more physically active, but also more prone to excess alcohol consumption (Arai et al., 2009; Magee et al., 2013; Vollrath et al., 1999). Extraverted individuals showed high compliance with COVID-19 mitigation measures in some studies (Aschwanden et al., 2020; Blagov, 2020; Bogg \& Milad, 2020), but exhibited lower mean levels of social distancing in others (Carvalho et al., 2020; Chen et al., 2020).

People scoring high in openness tend to seek new experiences, engage in self-examination, and exhibit intellectual curiosity and creativity. They tend to comprehend and follow medical advice and engage in more health promoting and less health risk behaviors (Beier \& Ackerman, 2003), however, they may also show propensity to risky sexual behaviors and drug abuse (Flory et al., 2002; Vollrath et al., 1999). Regarding the relationship between openness and COVID-19 guideline adherence, existing studies reported mixed results (Abdelrahman, 2020; Aschwanden et al., 2020; Bogg \& Milad, 2020; Blagov, 2020; Chen et al., 2020; Krupić et al., 2020; Martin, 2020; Stadler et al., 2020). 
Agreeableness, the tendency to be interested and considerate of others' needs and feelings, reflects prosociality, compassion, empathy, and cooperation. People scoring high in agreeableness are more optimistic about future health risks and less often engage in health risk behaviors (Ingledew \& Brunning, 1999; Vollrath et al., 1999). Individuals scoring high in agreeableness adhered more to COVID-19 guidelines in existing studies (Aschwanden et al., 2020; Bogg \& Milad, 2020; Chen et al., 2020; Clark et al., 2020; Stadler et al., 2020; Willroth et al. 2020; Zajenkowski et al., 2020).

Based on theory and existing evidence (Bogg \& Milad, 2020), it was expected to find that women, the elderly, essential workers, individuals with chronic health problems and those concerned about infection perceive the measures as more important and adhere to them more often. In relation to personality traits, individuals with high conscientiousness and agreeableness were expected to be more adherent to the measures (Bogg \& Roberts, 2004; Bogg \& Milad, 2020). There is less consensus on the effect of other three personality dimensions on compliance with COVID-19 mitigation measures, thus, this study had no a priori hypotheses regarding extraversion (energy), openness, and neuroticism.

\section{Methods}

\section{Survey and participants}

In Slovenia, the first SARS-CoV-2 infection was officially recorded on 4 March 2020. On 12 March 2020, the government officially declared an epidemic, resulting in a "lockdown", i.e., closed educational institutions, non-essential stores and services, halted public transport, and prohibition of physical gathering. Our survey started on 14 March 2020, during this "first wave" of the COVID-19 pandemic, via the online platform 1KA (version 20.03.02, University of Ljubljana, www.1ka.si) and it was distributed through social media networks (primarily Facebook and Twitter) for two weeks. Before entering the survey, participants were informed about the aims and duration of the study. The survey was anonymous and contented to GDPR. The survey was closed on 14 July 2020, but over 99\% of participants completed it before 20 April 2020, still during lockdown. A total of 2467 participants started the survey, of which 963 completed it (Table 1).

The survey consisted of three parts. The first part gathered the participants' demographic data, i.e., gender, age, education, settlement size, field and type of employment, and type of household (Table 1). The participants were then asked about their concern of contracting COVID-19 and concern of infecting others (both scored on the Likert scale: 1, not concerned to 5, strongly concerned), and their own chronic health conditions (e.g., high blood pressure, diabetes, cardiovascular disease, chronic respiratory disease, cancer, cerebrovascular and kidney diseases, weakened immune system, allergies, autoimmune diseases). They were also asked about health risks of their loved ones, including old age (i.e., over 65).

In the second part, the participants were asked about the importance of mitigation measures and guidelines in preventing the spread of COVID-19 (marked: important, unimportant, not sure; Tables 2- 
4). Then, they were asked how often they adhered to these mitigation measures and other health guidelines related to COVID-19 (marked: never, rarely, sometimes, often, always; Tables 5-6). Further, they were asked about their potential contacts with vulnerable individuals (i.e., people with chronic medical issues, weakened immune system or those older than 65 years) during lockdown (marked: meeting vulnerable individuals with or without respecting measures, or no contact; Table 7).

In the third part, the participants completed the adapted Slovenian version of the "Big Five Questionnaire" (BFQ; Caprara et al., 2012) which measures personality dimensions of extraversion (energy), conscientiousness, agreeableness, openness and neuroticism. It includes 132 statements, scored on a five-point Likert scale ranging from 1 (strongly disagree) to 5 (strongly agree). Reliability and construct validity of the dimensions are high, with Cronbach alpha coefficients for individual dimensions ranging from .75 to .85 . Since raw scores at some dimensions significantly differ in regard to sex and age, we used standardized T-values for the Slovene population in subsequent statistical analysis (Caprara et al., 2012) to ensure mutual comparability of regression coefficients.

\section{Data analyses}

It was first tested which factors affected the participants' attitude towards mitigation measures and guidelines, considered important in preventing the spread of COVID-19 (Table 2). Likelihood-ratio Chisquare test (with standardized residuals) was used to analyze whether the participants' concern of contracting COVID-19 (Table 3a), their concern of infecting others (Table 3a), demographic factors, household type, own health risks, and health risks of loved ones affected their attitude towards mandated and recommended measures and guidelines (Table 4).

Next, it was tested which factors affected the participants' implementation of mitigation measures (Table 5). Mann-Whitney U test or the Kruskal-Wallis H test were applied to analyze whether the participants' demographic factors, household type, own health risks and health risks of loved ones (Table 6), and the type of contact with vulnerable individuals during the pandemic (Table 7) affected their implementation of mitigation measures and other health guidelines related to COVID-19. For all independent variables except gender, the Games-Howell post-hoc multiple comparison test was performed to test which groups/classes/levels contributed to the significant Kruskal-Wallis H test. We applied the Jonckheere trend test to check for a significant trend in the degree of participants' concern and frequency of implementation of mitigation measures and other health guidelines related to COVID19 (Table 3b).

Finally, Kendall's Tau correlations were used to test whether the adherence to mitigation measures and guidelines was correlated to the five personality dimensions (Table 8). Kruskal-Wallis $\mathrm{H}$ test was used to analyze whether the participants' personalities related to if and how they met with vulnerable loved ones during the pandemic (see above).

\section{Results}




\section{The importance of the mitigation measures and guidelines to prevent the spread of COVID-19}

The participants found several measures and guidelines important in preventing the spread of COVID19 (Table 2). As important in limiting the spread of COVID-19, more than 90\% identified self-isolation in case of COVID-19 related symptoms or contact with a sick person, proper cough hygiene and hand washing/disinfection, regular indoor ventilation, keeping interpersonal distance, avoiding touching the face/mask with unwashed hands, and avoiding unnecessary contact with surfaces outside of home. On the other hand, less than $50 \%$ of participants identified alternative (online) shopping, separate clothing at home and outside, emptying the mailbox a day or two after receipt, using a protective mask outdoors, using a scarf/shawl instead of a mask, and using gloves as important measures.

The participants' concern of infection was the strongest predictor of trust in the relevance of COVID-19 prevention measures and guidelines (Table 3a). The more concerned the participants were, the more importance they placed on the selected measures and guidelines (Table 3a). Of the 1111 participants that answered this question, $38.1 \%$ were not concerned, $39.2 \%$ were slightly concerned, $16.2 \%$ were moderately concerned, $4 \%$ were considerably concerned and $2.5 \%$ were strongly concerned about getting infected. Similarly, the concern of infecting loved ones affected the participants' perception of almost all selected measures and guidelines (Table 3a). Of the 1108 participants, $22.2 \%$ were not concerned, $33.8 \%$ were slightly concerned, $22.2 \%$ were moderately concerned, $14.3 \%$ were considerably concerned and $7.5 \%$ were strongly concerned about infecting loved ones. The frequency of measure implementation related positively to the participants' concern of infection in 20 of the 25 guidelines, and to their concern of infecting loved ones in 21 of the 25 guidelines (Table $3 b$ ).

Men and women differed in perceived importance of several mitigating measures and guidelines (Table 4). Measures considered important by women more than men are discarding potentially infected objects into a special container (men: std. residual $=-1.2$ ), disinfection of surfaces at home (men: std. residual $=-2.7$ ), disinfection of areas shared by several households (men: std. residual $=-1.4$ ), having shopping done by a less vulnerable person (men: std. residual $=-1.6$ ), and separate clothing at home and outside (men: std. residual $=-1.5$ ). Measure considered ineffective by men more than women are regular indoor ventilation (men: std. residual $=2.9$ ), avoidance of enclosed spaces outside of home (men: std. residual $=3.3$ ), and regular replacement/disinfection of masks (men: std. residual $=1.6$ ) and gloves (men: std. residual $=1.4$ ).

The participants' age also affected the perceived importance of guidelines (Table 4). For example, participants younger than 30 years found the use of a mask outdoors (std. residual $=2.4$ ), the use a scarf/shawl (instead of a mask) outdoors (std. residual $=2.2$ ), use of gloves outdoors (std. residual $=2.8$ ), and having shopping done by a less vulnerable person (std. residual = 3.3) important more often than other age groups. In contrast, participants aged 51-70 years identified the shopping done by a less vulnerable person an irrelevant mitigation measure (51-60 years: std. residual $=2,61-70$ years: std. residual $=4.8$ ). Participants aged 30-40 years considered the following measures as ineffective more 
often: disinfection of surfaces at home (std. residual $=2.2$ ), disinfection of areas shared by several households (std. residual $=2.7$ ), use of a protective mask in enclosed spaces outside of home (std. residual $=2.4$ ). Less often, they considered the use of gloves to be effective (indoor use: std. residual = -2.5 ; outdoor use: std. residual $=-2$ ). Less participants aged $41-50$ found disinfection of packaging brought from the store (std. residual $=-2.3$ ) and emptying the mailbox a day or two after receipt (std. residual $=-2.2$ ) as relevant measures. Participants above 60 years considered the following measures as relevant more often: disinfection of surfaces at home $(61-70$ y.: std. residual $=2.5)$, disinfection of packaging brought from the store $(61-70$ y.: std. residual $=3.7 ;>70$ y.: std. residual $=2.4)$, separate clothing at home and outside ( $>70$ y.: std. residual $=2.3$ ), use of scarf/shawl instead of mask outdoors $(>70$ y.: std. residual $=2.2)$, use of gloves indoors $(61-70$ y.: std. residual $=2.6 ;>70 \mathrm{y} .:$ std. residual $=$ 2.6 ), and outdoors ( $>70$ y.: std. residual $=3.2$ ). Less participants aged over 60 found several measures ineffective, i.e., self-isolation after returning from abroad (std. residual $=-1.9$ ), discarding potentially infected objects in a special container (std. residual $=-1.8$ ), emptying the mailbox a day or two after receipt $(61-70$ y.: std. residual $=-2.2)$ and use of a protective mask indoors (std. residual $=-2.1)$.

The agreement with guidelines varied based on the participants' level of education (Table 4). More participants with primary school (std. residual $=2.3$ ) and lower secondary vocational school (std. residual $=3.1$ ) education thought self-isolation in case of COVID-19 related symptoms is unimportant. However, more participants with primary school education thought disinfection of surfaces at home (std. residual $=1.8$ ), using gloves indoors outside of home (std. residual $=2.2$ ) and emptying the mailbox a day or two after receipt (std. residual $=2.3$ ) are important guidelines. Participants with lower vocational school education found the use of a scarf/shawl instead of mask indoors (std. residual =1.4) important more often. The share of participants in support of having shopping done by a less vulnerable person increased with their education level (important, master's degree: std. residual $=2$; unimportant, primary school: std. residual $=2.4$ ), while support of using gloves indoors decreased with increased education level (important, primary school: std. residual $=2.6$; master's degree: std. residual $=-2.6$ ).

Based on settlement size, the participants differed little in perceived importance of selected guidelines (Table 4). More participants from the smallest settlements thought it is important to use a mask (std. residual $=2$ ) and gloves (std. residual $=2.8$ ) indoors outside of home.

More retired participants (std. residual $=3.2$ ) and working students ( std. residual $=2.5$ ) believed that disinfection of packaging from the store is important. Retirees (std. residual $=2.4$ ) and students (not working: std. residual $=2.2$, working: std. residual $=3.5$ ) also believed the use of a scarf/shawl instead of a mask outdoors, to be important more often. Similarly, students (not working: std. residual $=2.5$, working: std. residual $=3.2$ ) and the unemployed (std. residual $=3.2$ ) trusted in the use of gloves outdoors as a mitigating measure, while the opposite was true for the self-employed (std. residual = 2.2). Less retired participants thought that having shopping done by a less vulnerable person (std. residual $=-2.9$ ) is important, whereas less working students (std. residual $=-1.8$ ) and employees of the public sector on a limited contract (std. residual $=-2.1$ ) perceived this measure as important. More 
students (not working: std. residual $=2.5$, working: std. residual $=3.2$ ), freelance workers (std. residual $=2.1$ ) and unemployed (std. residual $=1.9$ ) found the use of a mask indoors outside of home important. On the other hand, this measure seemed important to fewer people working in the private sector on a permanent contract (std. residual $=-2.3$ ). The retired trusted the importance of the use of gloves indoors (std. residual =3) more often, while the opposite was true for participants working in the private sector on a limited contract (std. residual $=-2.1$ ). Participants working in banks and post offices more often found self-isolation in case of contact with an infected person important (std. residual =5). Additionally, more participants working in economics (std. residual $=2.5$ ), culture, science, and sports (std. residual $=2.3$ ) found regular indoor ventilation unimportant.

Participants from various household types did not differ in perceived importance of most guidelines. However, disinfection of surfaces at home was viewed as unimportant more often by those living in single-parent households (std. residual $=1.5$ ), while participants living with a spouse were more likely to perceive the use of a scarf/shawl instead of a mask outdoors as important (std. residual = 1.8). In comparison, participants with chronic diseases more often considered disinfection of packaging from the store important (std. residual $=2.1$ ), but less often thought that use of a mask indoors is important (std. residual $=-1.8$ ). The latter was also true for those with autoimmune diseases (std. residual $=-1.9$ ). Participants with a compromised immune system (std. residual $=-1.6$ ) and those without chronic diseases (std. residual $=-1.7$ ) found regular indoor ventilation less important.

The perceived importance of six guidelines depended on the health status and age of the participants' loved ones. If their loved ones were older and/or had three or more health problems, less participants considered important the disinfection of packaging from the store (std. residual $=-2.8$ ), use of gloves indoors outside of home (std. residual $=-2.5$ ), regular replacement/disinfection of gloves (std. residual $=-2.3$ ). These participants more often trusted the importance of emptying the mailbox a day or two after receipt (std. residual $=2.1$ ) and the use of a protective mask indoors (std. residual $=2.5$ ). When the participants' loved ones were older than 65 and/or had two health problems, they more often considered unimportant the use of a protective mask outdoors (std. residual $=-2.2$ ) and regular replacement/disinfection of gloves (std. residual $=2.0$ ). When their loved ones had a weakened immune function, the participants found emptying the mailbox a day or two after receipt (std. residual $=2.2$ ) and the use of gloves indoors outside of home (std. residual =1.6) as important more often, but considered regular replacement/disinfection of gloves as important less often $($ std. residual $=-1.8$ ).

\section{Adherence to the mitigation measures and guidelines to prevent the spread of COVID-19}

The participants implemented the selected measures and guidelines to prevent the spread of COVID-19 with markedly different frequencies (Table 5). Eleven of the 25 selected measures were performed regularly by more than $50 \%$ of participants, while five measures were never implemented by more than $50 \%$ of participants (Table 5). 
Men and women differed in the frequency of implementation of 12 guidelines (Table 6), with women consistently employing these measures more often than men. The implementation of 16 guidelines differed among age classes (Table 6). Generally, people over 50 years adhered to guidelines more often than younger participants. Younger participants, on the other hand, were stricter at respecting the set shopping hour restrictions.

Education level only had a significant effect on compliance with four guidelines (Table 6). Participants with higher degrees of education (doctorate, master's degree) more frequently limited themselves to contact with household members only. In contrast, the frequency of disinfection of surfaces at home and use of gloves indoors was inversely proportional to education level.

Based on settlement size, compliance with health guidelines differed in three cases (Table 6). Inhabitants of larger settlements more frequently limited themselves to contact with household members only and used gloves (in enclosed spaces outside and outdoors) more often.

Participants with different types of employment differed in the frequency of guideline implementation in several cases (Table 6). Retired participants discarded potentially infected objects into a special container, disinfected surfaces at home and wiped/disinfected packing from the store more often than the self-employed, public sector (permanent and fixed-term) and private sector workers (permanent). Retirees also adhered to disinfection of areas shared by several households more regularly than the self-employed and those working in the private sector (permanent). Further, retirees avoided enclosed spaces outside of home more often than private sector employees (permanent). Retirees, students, and the self-employed used gloves indoors more often. Students more often complied with having shopping done by a less vulnerable person than self-employed and public sector employees (permanent and fixed-term) and private sector employees (permanent). Public (permanent and fixedterm) and private sector (permanent) employees less often adhered to proper cough hygiene than freelance workers. Public sector employees also less often applied proper hand hygiene than those from the public sector (permanent). Similarly, participants from different employment fields differed in the adherence of only three guidelines (Table 6). Participants working in education and healthcare adhered to the rules of cough hygiene more often than participants who did not disclose their employment field. Participants working in culture, sciences, and sport discarded potentially infected objects into a special container less often than those working in service (e.g., hospitality, hairdressing, mechanics). Participants working in commerce, industry, banking, and post offices used a scarf/shawl instead of a mask outdoors more frequently than others.

Compliance with guidelines generally did not differ across household types (Table 6). Participants living with a spouse more frequently limited themselves to contact with household members only than those living with extended family. Participants living with family used alternative (online) shopping methods, had shopping done by a less vulnerable person and avoided enclosed spaces outside home more frequently than those living alone. Participants living with siblings, roommates, etc. 
complied to the guideline of having shopping done by a less vulnerable person less frequently than others.

Medical problems did not present a major factor influencing guideline compliance except in three cases (Table 6). Participants with chronic diseases had shopping done by a less vulnerable person and used a scarf/shawl instead of a mask outdoors more often than those with allergies, asthma, cancer, pregnant women, and healthy participants. The latter also used a scarf/shawl instead of a mask outdoors more frequently than participants with allergies, asthma, cancer, and pregnant women.

The health status and age of the participants' loved ones was a relatively important factor, influencing the implementation of seven guidelines (Table 6). When the participants' loved ones had a weakened immune system, participants disinfected surfaces at home more often. They also more regularly replaced/ disinfected gloves. When the participants' loved ones had three or more health problems and/or were old, they wiped/disinfected packaging from the store, used a protective mask outdoors, used gloves indoors and outdoors, and regularly replaced/ disinfected gloves more often compared to participants whose loved ones had two health problems and/or were old. Participants with loved ones with a weakened immune system or those employed in healthcare more often emptied the mailbox a day or two after receipt.

Participants who were in contact with a vulnerable person while respecting social distancing, also more frequently performed several guidelines, i.e., proper hand washing and replacement/ disinfection of masks than participants who had not respected mitigating measures and those without contact with vulnerable people (Table 7). Participants who had not respected health guidelines during such meetings regularly ventilated indoor spaces, kept a safe interpersonal distance and avoided touching the face and mask less often. Participants who had met chronically ill persons without respecting health guidelines also less often emptied the mailbox a day or two after the delivery and used a protective mask outdoors less. Those without such contacts, in contrast, used a scarf/shawl instead of a mask indoors outside of home more often. The contact type of participants with loved ones with a weakened immune system did not relate to general adherence to mitigation measures. Participants who had been in contact with a person older than 65 without respecting health guidelines less often implemented several other measures, too, i.e., they less often properly washed hands, respected shopping hour restrictions, kept safe interpersonal distance, avoided indoor spaces outside of home and avoided touching face and mask with unwashed hands less often (Table 7). Participants who had no contact with an elderly person more frequently limited physical contacts to household members only and emptied the mailbox a day or two after receipt.

\section{Personality dimensions and adherence to the measures and guidelines to mitigate COVID-19}

Adherence to the measures and guidelines to mitigate COVID-19 were considerably related to the participants' personality traits, especially conscientiousness (Table 8). Two measures, the proper hand disinfection and avoiding touching the face and mask with unwashed hands, correlated positively to 
scorings of each personality. Participants scoring low in conscientiousness less often adhered to these two measures compared to those with high score in conscientiousness. The same was true for keeping a safe interpersonal distance, except for neuroticism where we found no significant correlation. Discarding potentially infected objects into a special container also correlated positively with all personality dimensions except energy.

Conscientious participants followed several measures more closely than participants scoring low in conscientiousness, mostly related to the use of mask and gloves, disinfection and avoidance of potentially infected surfaces and places (Table 8). Similarly, proper cough hygiene positively correlated to conscientiousness, agreeableness, and openness. Conscientious and open participants more often limited physical contacts to household members only and wiped/disinfected packaging from the store than participants of low conscientiousness and openness ones. Surface disinfection at home positively correlated to conscientiousness and energy. Energy was positively correlated to regular indoor ventilation and negatively to having shopping done by a less vulnerable person. Open participants used alternative (online) shopping methods more frequently than the conservative.

Six of the 25 guidelines showed no relation to personality (Table 8). Participants with different personalities did not differ in whether and how (with or without respecting health guidelines) they met vulnerable people during the lockdown, i.e., those with chronic medical issues, a weakened immune system, or people over 65 years old.

\section{Discussion}

This study addressed the perception and compliance with COVID-19 mitigation measures and guidelines among adult Slovenians during the first wave of the epidemic. It was examined which sociodemographic, psychological, and personality factors were associated with the participants' attitudes toward and compliance with the measures. In general, the strongest predictors of confidence in preventive measures and their implementation were the participants' concern of infecting themselves and their loved ones, followed by gender and age. Also, adherence to the measures was positively related to personality trait scores - highly conscientious participants adhered to guidelines more often, as did those scoring high in openness.

Participants considered several of the 28 preventive measures as highly important. Namely, more than 90\% endorsed self-isolation in case of COVID-19-related symptoms and self-isolation in case of contact with a person with COVID-19 (both of which were mandatory, along with self-isolation after returning from abroad), adherence to the rules of cough hygiene, regular and thorough hand washing/disinfection, regular indoor ventilation, keeping a safe interpersonal distance, avoiding touching the face and mask with unwashed hands and avoiding unnecessary contact with surfaces outside. These findings are consistent with similar studies from other countries. In the UK, participants listed frequent hand washing with soap and water (92.5\%), avoiding contact with people experiencing fever and/or respiratory symptoms (91.4\%), and cough hygiene (90.0\%) as most effective measures 
(Atchison et al., 2020). However, only $85.5 \%$ of participants reported washing their hands with soap frequently, suggesting participants' confidence in the measures was somewhat higher than their actual compliance. The participants in the present study reported similarly high (sometimes even higher) levels of agreement with the measures, while the levels of considered measure importance were higher than the levels of adherence. High levels of agreement with measures and guidelines are also reported from Italy (Barari et al., 2020), the USA (Park et al., 2020), France (Brouard et al., 2020), and on an international level (Clark et al., 2020).

In this study, $83 \%$ of participants often $(29.5 \%)$ or always (55.5\%) adhered to one of the most basic preventive measures, limiting physical contact to members of the household. This is consistent with Italians, who endorsed avoiding social gatherings and physical contact with people outside their household in more than 90\% (Barari et al., 2020). In contrary, only $45.2 \%$ of respondents in the UK adhered to social distancing measures, e.g., avoiding crowded places and social events (Atchison et al., 2020). Among US Americans, there are high levels of agreement with some aspects of restricting physical contact, i.e., discreet traveling (89.7\%) and keeping a safe interpersonal distance (87.4\%; Park et al., 2020). Predictably, the greater the participants' concern of infecting themselves or their loved ones, the more importance they placed on the measures and guidelines, which they implemented more frequently. These findings are consistent with reports of strong correlation between fear of COVID-19 and related safety behaviors (Knowles \& Olatunji, 2020).

Among sociodemographic factors, gender was the most relevant predictor of measure compliance. Women considered more measures important and adhered to them more. This is consistent with the findings of Barari et al. (2020), Park et al. (2020) and Clark et al. (2020), all of which reported higher levels of compliance among women than men.

Several studies report that younger generations adhered to measures less (Atchison et al., 2020; Barari et al., 2020; Brouard et al., 2020; Park et al., 2020). For example, young Italians (18-29 years) complied to hand washing and social distancing significantly less often (Barari et al., 2020). In contrast, the youngest age group (18-29 years) in the present study did not confide less in any guideline. In fact, this age group even perceived some of guidelines (e.g., the use a protective mask or scarf outdoors and having shopping done by a less vulnerable person) more important. This might suggest larger awareness of the importance of health guidelines among the younger generation, below age of 30 , in Slovenia and its commitment to protecting the vulnerable. Interestingly, the recommendation to have someone less vulnerable do one's shopping was perceived as irrelevant mainly by the older population (50-70 years), perhaps because they do not wish to be a burden to others or because they might perceive this as an inability to function in society. The greatest deviation (albeit in only five of the 25 guidelines) in perceived effectiveness of measures was found among participants aged 30-40 years. Of the five, their lack of confidence in disinfecting areas shared by multiple households and the use of a protective mask in enclosed spaces outside of home, may be the most problematic and potentially contributing factors to the spread of COVID-19. 
Participants over 60 years considered six of the 25 measures to be relevant more often, and four of 25 relevant less often. It was expected to find an increased perceived importance of measures among the old, as they are most likely to require medical assistance in case of infection. Surprisingly however, these participants trusted less in the importance of self-isolation after returning from abroad (despite neighboring countries having several fold more confirmed cases during the first wave) and in the importance of wearing masks in enclosed spaces outside of home. While their perceived importance with these two guidelines was lower, their compliance with them was not. Their lower perceived importance of mask wearing may be explained by breathing difficulties experienced by the oldest participants, as well as ambiguous expert reports regarding mask efficacy and a relatively small infection rate at that time.

Based on education, employment type and field, household type, and health status, participants predictably differed in their confidence and adherence to measures and guidelines. Particularly concerning, significantly more participants with primary education stated that self-isolation in case of COVID-19 symptoms is not important, when in fact it might be the most important of all. Participants with higher level education were more likely to limit physical contact to household members. This may be at least partially attributed to highly educated people being able to work from home more often, and thus avoid physical contacts at the workplace. Additionally, the support for having shopping done by a less vulnerable person increased with the education level.

Personality traits played an important role in compliance behavior. As expected based on existing literature (Abdelrahman, 2020; Aschwanden et al., 2020; Bogg \& Milad, 2020; Blagov, 2020, Carvalho et al., 2020; Krupić et al., 2020), conscientiousness was the greatest predictor of compliance with COVID-19 mitigation measures and guidelines. Participants scoring high in conscientiousness more often adhered to measures and guidelines, including those less commonly practiced by the majority, such as disinfecting surfaces shared by multiple households, and using protective masks outdoors. This is not surprising, as conscientiousness directly relates to following rules, taking responsibility, refraining from risky behaviors and practicing a healthy lifestyle (Bogg \& Roberts, 2004; Aschwanden et al., 2019).

The second most relevant personality predictor of compliance behavior was openness. Individuals who scored high in openness more often adhered to measures such as using alternative (online) shopping methods and limiting physical contact to household members. Such a positive correlation might be related to a general positive attitude, a motivation to learn and experience new things, and thus a greater behavioral flexibility of open-minded individuals. While open-minded individuals are generally more likely to seek health-related information and understand and follow medical advice (Baier \& Ackerman, 2003; Bogg \& Vo, 2014), COVID-19 studies provide mixed results. Openness correlated positively with COVID-19 guideline adherence in some studies (Aschwanden et al., 2020; Bogg \& Milad, 2020), but not others (Abdelrahman, 2020; Blagov et al., 2020; Krupić, Žuro, \& Krupić, 2020; Zajenkowski et al., 2020). 
Emotional stability also shows a positive correlation to basic protective measures, e.g., washing/disinfecting hands, maintaining a safe interpersonal distance, and avoiding touching the face/mask with unwashed hands. Even though agreeableness proved to be a predictor of measure adherence in this study, its effect was not as predominant as in some other studies, where it was identified as the most important predictor of adherence, along with conscientiousness (Aschwanden et al., 2020; Blagov et al., 2020; Bogg \& Milad, 2020; Clark et al., 2020; Krupić et al., 2020; Zajenkowski et al., 2020).

There is less consensus on the effect of neuroticism on the adherence to mitigation measures, considering it was found to be negatively related to precautious behaviors in the USA (Aschwanden et al., 2020; Bogg \& Milad, 2020), but positively in Qatar (Abdelrahman, 2020), while several studies found no significant association (Blagov et al., 2020; Krupić et al., 2020; Willroth et al., 2020; Zajenkowski et al., 2020). Extraversion, too, remains an ambiguous predictor of measure conformity. It correlated positively with most queried precautionary behaviors in the USA (Aschwanden et al., 2020; Bogg \& Milad, 2020), while in Brazil, extraverts were found less likely to adhere to social distancing than introverts (Carvalho et al., 2020). Several other studies found no such relationship (Blagov et al., 2020; Krupić et al., 2020; Zajenkowski et al., 2020). The results of the present study suggest that extraverts do keep a safe interpersonal distance, but do not limit physical contacts to members of their household. Extraverted participants thus seem aware of the necessity of restrictive measures, but do not always resist socialization with friends and extended family.

\section{Implications}

The main objective of the present study was to understand how people perceived and adhered to measures and guidelines intended to mitigate the spread of COVID -19 and to examine what demographic, psychological, and personality characteristics influenced people's perceptions of and compliance with the measures. Understanding these relationships can help decision makers appropriately determine interventions and communicate them more effectively now and in the future. By integrating several domains of research, this study contributes to the fields of psychology, sociology, crisis management, and government policing.

The findings suggest that the primary factor influencing support and compliance with the measures is concern for one's own health and that of loved ones. Therefore, measures should likely be communicated in a way that emphasizes health values, rather than in a way that incites fear. Positive communication could be more effective for both measure adherence and well-being. In addition, young people (aged 18-29) were more complaint with some of the measures and expressed helping others (including outside the family) as a value. This should be used to promote more proactive policies and guidelines that can boost self-worth. Young people tend to be energetic, so it can be frustrating if they are only allowed to follow restrictions. 
Previous findings on the association between agreeableness and energy (extraversion) and measure adherence have been inconsistent. Here, it is suggested that agreeable and energetic individuals may also benefit from more proactive measures. Individuals with higher extraversion need more action and dynamics in their lives, and individuals with higher agreeableness need social interactions to feel more fulfilled. Being able to feel beneficial seems to be important for adhering to measures in general, even if they are perceived as less important.

Participants aged 30-40 years did not adhere to one of the most important measures, the use of a protective mask in enclosed places away from home. This generation has a lower risk of a severe form of COVID -19, health may not be their primary concern, on the other hand they have higher psychological pressure due to workload at home and at work. This may represent a psychological conflict that they resolve with defense mechanisms of rationalization, a reduction in the importance of those measures that most limit their quality of life. Therefore, measures should be adapted to cause less psychological conflict.

Individuals with lower (primary) education did not consider self-isolation in case of COVID -19 symptoms and limitation of physical contact to household members as important measures to mitigate spread of the virus. This could be due to less effective communication by the government. First, there may be too many measures and guidelines being recommended. With so many measures imposed, their ranking of importance may be mixed and more susceptible to personal interpretation. Second, SARS-CoV-2 has a longer incubation period and possible asymptomatic disease development, which may be somewhat counterintuitive. Therefore, this should be explained and emphasized more. It should be explained clearly and consistently enough how the most important measures relate to the transmission of the disease. Often such explanations are too long, too complicated and without concrete examples.

\section{Strengths and limitations}

The present study has several strengths. The data set is large and comprehensive, and the survey was fully completed by 963 participants. Importantly, the data were collected during the lockdown in the first wave of the COVID-19 pandemic, so it recorded the first response to an "unexpected disaster". In addition to various demographic factors, the participants were surveyed on their perception of the majority of the enforced measures as well as recommended guidelines, intended to mitigate the spread of COVID-19, while other studies usually only include a selected few. To ensure cross-comparability of results, standardized T-scores for the Slovenian population instead of raw scores at personality questionnaire were used in the analyses. This study also has limitations. All participants were Slovenians, and it remains unclear whether similar patterns hold true in other cultural contexts. In addition, the sample was biased towards individuals with higher education, and working in the fields of culture, education, and science, likely due to online data collection. Specifically, individuals who are less likely to use the internet regularly, may be underrepresented in the sample. Finally, this study was based on self-report scales rather than actual behavior, so the participants' responses may be biased 
towards socially desirable responses. Future studies should incorporate other mediators of positive health behaviors, such as states of mind (Herz, Baror, \& Bar, 2020), mental toughness, defense mechanisms, and a broader emotional response, including a detailed stress response, to better understand the relationship between personality, stress, and behavior. It would also be important to follow individuals longitudinally.

\section{Conclusions}

The current COVID-19 pandemic caught the decision makers in many countries sub-optimally prepared to respond. To better cope with similar situations in the future, it is vital to understand the major predictors of health-beneficial behavior and adherence to imposed mitigation measures and guidelines. To tailor the promotion of government-imposed measures and guidelines, it is important to understand how the sociodemographic background combined with personality traits affect the perception and responsiveness of people. In the present study, the strongest predictors of confidence and adherence to preventive measures were the participants' concern of infecting themselves and their loved ones, followed by gender and age. Adherence was also related to personality traits: highly conscientious participants were more likely to adhere to the guidelines, as were those who scored high in openness. Individuals between the ages of 30 and 40 and those with a lower education level were less likely to adhere to the measures, including the most important ones, suggesting more attention should be paid to communicating the importance of the measures to these groups in an effective manner. The insights of this study can prove useful in the development and customization of future guidelines and measures concerning public health in Slovenia.

\section{References}

Abdelrahman, M. (2020). Personality Traits, Risk Perception, and Protective Behaviors of Arab Residents of Qatar During the COVID-19 Pandemic. International Journal of Menthal Health and Addiction. https://doi.org/10.1007/s11469-020-00352-7

Arai, S., Nakaya, N., Kakizaki, M., Ohmori-Matsuda, K., Shimazu, T., Kuriyama, S., ... \& Tsuji, I. (2009). Personality and gastric cancer screening attendance: a cross-sectional analysis from the Miyagi Cohort Study. Journal of epidemiology, 0901160055-0901160055. https://doi.org/10.2188/jea.JE20080024

Aschwanden, D., Gerend, M. A., Luchetti, M., Stephan, Y., Sutin, A.R., \& Terracciano, A. (2019). Personality traits and preventive cancer screenings in the health retirement study. Preventive Medicine, 126, 105763. https://doi.org/10.1016/j.ypmed.2019.105763 
Aschwanden, D., Strickhouser, J. E., Sesker, A. A., Lee, J. H., Luchetti, M., Stephan, Y., Sutin, A. R., \& Terracciano, A. (2020). European Journal of Personality, https://doi.org/10.1002/per.2281

Atchison, C. J., Bowman, L., Vrinten, C., Redd, R., Pristerà, P., Eaton, J. W., \&Ward, H. (2020). Perceptions and behavioural responses of the general public during the COVID-19 pandemic: A crosssectional survey of UK Adults. Preprint from medRxiv. https://doi.org/10.1101/2020.04.01.20050039

Barari, S., Caria, S., Davola, A., Falco, P., Fetzer, T., Fiorin, S., Hensel, L., Ivchenko, A., Jachimowicz, J., King, K., Kraft-Todd, G., Ledda, A., MacLennan, M., Mutoi, L., Pagani, C., Reutskaja, E., Roth, C., \& Slepoi, R. F. (2020). Evaluating COVID-19 Public Health Messaging in Italy: Self-Reported Compliance and Growing Mental Health Concerns. Preprint from medRxiv. https://doi.org/10.1101/2020.03.27.20042820

Beier, M. E., \& Ackerman, P. L. (2003). Determinants of health knowledge: An investigation of age, gender, abilities, personality, and interests. Journal of Personality and Social Psychology, 84(2), 439448. https://doi.org/10.1037/0022-3514.84.2.439

Blagov, P. S. (2020). Adaptive and Dark Personality in the COVID-19 Pandemic: Predicting HealthBehavior Endorsement and the Appeal of Public-Health Messages. Social Psychological and Personality Science, https://doi.org/10.1177/1948550620936439

Bogg, T., \& Milad, E. (2020). Demographic, Personality, and Social Cognition Correlates of Coronavirus Guideline Adherence in a U.S. Sample. Health Psychology, 39(12), 1026-1036. http://dx.doi.org/10.1037/hea0000891

Bogg, T., \& Roberts, B. W. (2004). Conscientiousness and Health-Related Behaviors: A Meta-Analysis of the Leading Behavioral Contributors to Mortality. Psychological Bulletin, 130(6), 887-919. https://doi.org/10.1037/0033-2909.130.6.887

Bogg, T., \& Vo, P. T. (2014). Openness, neuroticism, conscientiousness, and family health and aging concerns interact in the prediction of health-related Internet searches in a representative US sample. Frontiers in psychology, 5, 370. https://doi.org/10.3389/fpsyg.2014.00370

Brouard, S., Vasilopoulos, P., \& Becher, M. (2020). Sociodemographic and Psychological Correlates of Compliance with the COVID-19 Public Health Measures in France. Canadian Journal of Political Science, 53, 253-258. https://doi.org/10.1017/S0008423920000335 
Caprara, G.V., Barbaranelli, C., Borgogni, L., Bucik, V., Boben, D., Hruševar-Bobek, B., Krajnc, I., Zupančič, M., \& Horvat, M. (2012). BFQ: Model "velikih pet": pripomočki za merjenje strukture osebnosti : priročnik. 3. dopolnjena izd. Ljubljana: Center za psihodiagnostična sredstva

Carvalho, L. F., Pianowski, G., \& Gonçalves, A. P. (2020). Personality differences and COVID-19: are extroversion and conscientiousness personality traits associated with engagement with containment measures? Trends in Psychiatry and Psychotherapy, 42(2), 179-184. https://doi.org/10.1590/2237$\underline{6089-2020-0029}$

Chen, S., Yang, J., Yang, W., Wang, C., \& Bärnighausen, T. (2020). COVID-19 control in China during mass population movements at New Year. The Lancet, 395(10226), 764-766. https://doi.org/10.1016/S0140-6736(20)30421-9

Clark, C., Davila, A., Regis, M., \& Kraus S. (2020). Predictors of COVID-19 voluntary compliance behaviors: An international investigation. Global Transitions, 2, 76-82. https://doi.org/10.1016/j.glt.2020.06.003

Costa, P. T., \& McCrae, R. R. (1985). Hypochondriasis, neuroticism, and aging: When are somatic complaints unfounded? American Psychologist, 40(1), 19-28. https://doi.org/10.1037/0003$\underline{066 X .40 .1 .19}$

Flory, K., Lynam, D., Milich, R., Leukefeld, C., \& Clayton, R. (2002). The relations among personality, symptoms of alcohol and marijuana abuse, and symptoms of comorbid psychopathology: Results from a community sample. Experimental and Clinical Psychopharmacology, 10(4), 425-434. https://doi.org/10.1037/1064-1297.10.4.425

Friedman, H. S., Tucker, J. S., Schwartz, J. E., Martin, L. R., Tomlinson-Keasey, C., Wingard, D. L., \& Criqui, M. H. (1995). Childhood conscientiousness and longevity: Health behaviors and cause of death. Journal of Personality and Social Psychology, 68(4), 696-703. https://doi.org/10.1037/00223514.68.4.696

Gale, C. R., Čukić, I., Batty, G. D., McIntosh, A. M., Weiss, A., \& Deary, I. J. (2017). When Is Higher Neuroticism Protective Against Death? Findings from UK Biobank. Psychological Science, 28(9), 1345-1357. https://doi.org/10.1177/0956797617709813 
Hakulinen, C., Hintsanen, M., Munafò, M. R., Virtanen, M., Kivimäki, M., Batty, G. D., \& Jokela, M. (2015). Personality and smoking: individual-participant meta-analysis of nine cohort studies. Addiction, 110(11), 1844-1852. https://doi.org/10.1111/add.13079

Herz, N., Baror, S., \& Bar, M. (2020). Overarching States of Mind. Trends in Cognitive Sciences, 24(3), 184-199. https://doi.org/10.1016/j.tics.2019.12.015

Ingledew, D. K., \& Brunning, S. (1999). Personality, preventive health behaviour and comparative optimism about health problems. Journal of Health Psychology, 4, 193-208. https://doi.org/10.1177/135910539900400213

Knowles, K. A., \& Olatunji, B. O. (2020). Anxiety and safety behavior usage during the COVID-19 pandemic: The prospective role of contamination fear. Journal of anxiety disorders, 77, 102323.

Krupić, D., Žuro, B., \& Krupić, D. (2020). Big Five traits, approach-avoidance motivation, concerns and adherence with COVID-19 prevention guidelines during peak of pandemics in Croatia. Preprint from PsyArXiv. https://doi.org/10.31234/osf.io/3edyb

Magee, C. A., Miller, L. M., \& Heaven, P. C. L. (2013). Personality trait change and life satisfaction in adults: The roles of age and hedonic balance. Personality and Individual Differences, 55(6), 694-698. https://doi.org/10.1016/j.paid.2013.05.022

Martin, C. C. (2020). HEXACO Traits, Big Five Traits, and COVID-19. Preprint from PsyArXiv PsyArXiv; 2020. doi:10.31234/osf.io/c9gxe

McCrae, R. R., \& Costa, P. T. (2006). Personality in adulthood: A five-factor theory perspective (2nd ed.). New York, NY, USA: Guilford Press.

Molloy, G. J., O'Carroll, R. E., \& Ferguson, E. (2014). Conscientiousness and Medication Adherence: A Meta-analysis. Annals of Behavioral Medicine, 47(1), 92-101. https://doi.org/10.1007/s12160-013$\underline{9524-4}$

Mroczek, D. K., Spiro, A., \& Turiano, N. A. (2009). Do health behaviors explain the effect of neuroticism on mortality? Longitudinal findings from the VA Normative Aging Study. Journal of Research in Personality, 43(4), 653-659. https://doi.org/10.1016/j.jrp.2009.03.016 
Park, C. L., Russell, B. S., Fendrich, M., Finkelstein-Fox, L., Hutchison, M., \& Becker J. (2020). Americans' COVID-19 Stress, Coping, and Adherence to CDC Guidelines. Journal of General Internal Medicine, 35, 2296-2303. https://doi.org/10.1007/s11606-020-05898-9

Stadler, M., Niepel, C., Botes, E., Dörendahl, J., Krieger, F., \& Greiff, S. (2020). Individual Psychological Responses to the SARS-CoV-2 Pandemic: Different Clusters and Their Relation to RiskReducing Behavior. Preprint from PsyArXiv. https://doi.org/10.31234/osf.io/k8unc

Sutin, A. R., Stephan, J., Grzywacz, J. G., Robinson, E., Daly, M., \& Terracciano, A. (2016). Perceived weight discrimination, changes in health, and daily stressors. Obesity, 24(10), 2202-2209. https://doi.org/10.1037/a0024286

van Rooij, B., Bruijn, A. L., Folmer, C. R., Kooistra, E., Kuiper, M. E., Brownlee, M., Olthuis, E., \& Fine, A. (2020). Compliance with COVID-19 Mitigation Measures in the United States. Preprint from PsyArXiv. https://doi.org/10.31234/osf.io/qymu3

Vollrath, M., Knoch, D., \& Cassano, L. (1999). Personality, risky health behaviour, and perceived susceptibility to health risks. European Journal of Personality, 13(1), 39-50. https://doi.org/10.1002/(SICI)1099-0984(199901/02)13:1<39::AID-PER328>3.0.CO;2-J

Vollrath, M., \& Torgersen, S. (2002). Who takes health risks? A probe into eight personality types. Personality and Individual Differences, 32(7), 1185-1197. https://doi.org/10.1016/S0191$\underline{8869(01) 00080-0}$

Weston, S. J., \& Jackson, J. J. (2018). The role of vigilance in the relationship between neuroticism and health: A registered report. Journal of Research in Personality, 73, 27-34. https://doi.org/10.1016/j.jp.2017.10.005

Willroth, E. C., Smith, A. M., Shallcross, A. J., Graham, E. K., Mroczek, D. K., \& Ford, B. Q. (2020). The Health Behavior Model of Personality in the Context of a Public Health Crisis. Preprint from PsyArXiv. https://doi.org/10.31234/osf.io/mu3ja

Zajenkowski, M., Jonason, P. K., Maria Leniarska, M., \& Kozakiewicz, Z. (2020). Who complies with the restrictions to reduce the spread of COVID-19?: Personality and perceptions of the COVID-19 $\begin{array}{llllll}\text { situation. Personality and Individual Differences, } & 166, & 110199 .\end{array}$ https://doi.org/10.1016/j.paid.2020.110199 


\section{Tables}

\section{Table 1}

Frequencies and percentages of survey participants by gender, age class, education, settlement size, and employment field and type.

\begin{tabular}{|c|c|c|}
\hline Parameter & Frequency & Percentage (\%) \\
\hline \multicolumn{3}{|l|}{ Gender } \\
\hline Male & 432 & 34.3 \\
\hline Female & 827 & 65.7 \\
\hline \multicolumn{3}{|l|}{ Age } \\
\hline up to 30 years & 278 & 22.1 \\
\hline $31-40$ years & 354 & 28.1 \\
\hline $41-50$ years & 372 & 29.5 \\
\hline $51-60$ years & 150 & 11.9 \\
\hline $61-70$ years & 79 & 6.3 \\
\hline 71 years or more & 27 & 2.1 \\
\hline \multicolumn{3}{|l|}{ Education } \\
\hline Primary school & 16 & 1.3 \\
\hline Lower secondary vocational school & 26 & 2.1 \\
\hline Secondary or general vocational school & 255 & 20.5 \\
\hline Higher education ( $1^{\text {st }}$ Bologna level $)$ & 229 & 18.4 \\
\hline Higher education ( $2^{\text {nd }}$ Bologna level or 4 -year university study) & 468 & 37.7 \\
\hline Master of Science or $\mathrm{PhD}$ & 249 & 20.0 \\
\hline \multicolumn{3}{|l|}{ Settlement size } \\
\hline Up to 500 inhabitants & 160 & 12.9 \\
\hline $500-1.000$ inhabitants & 91 & 7.3 \\
\hline $1.000-5.000$ inhabitants & 191 & 15.4 \\
\hline $5.000-10.000$ inhabitants & 140 & 11.3 \\
\hline $10.000-20.000$ inhabitants & 98 & 7.9 \\
\hline $20.000-50.000$ inhabitants & 60 & 4.8 \\
\hline $50.000-100.000$ inhabitants & 43 & 3.5 \\
\hline More than 100.000 inhabitants & 459 & 37.0 \\
\hline \multicolumn{3}{|l|}{ Employment type } \\
\hline Student - I rarely/do not work through student service & 37 & 3.1 \\
\hline Student - I regularly work through student service & 56 & 4.6 \\
\hline I mostly work on freelance contracts & 8 & 0.7 \\
\hline Self-employed & 120 & 9.9 \\
\hline Public sector - fixed term & 120 & 9.9 \\
\hline Public sector - permanent & 392 & 32.5 \\
\hline Private sector - fixed term & 41 & 3.4 \\
\hline Private sector - permanent & 290 & 24.0 \\
\hline Retired & 83 & 6.9 \\
\hline Unemployed & 52 & 4.3 \\
\hline Other & 8 & 0.7 \\
\hline \multicolumn{3}{|l|}{ Employment field } \\
\hline Education & 112 & 9.7 \\
\hline Tourism & 46 & 4.0 \\
\hline Healthcare & 73 & 6.3 \\
\hline Commerce & 68 & 5.9 \\
\hline Service (e.g., hospitality, hairdressing, mechanics) & 66 & 5.7 \\
\hline Industry & 69 & 6.0 \\
\hline Media & 45 & 3.9 \\
\hline Culture, science, sports & 294 & 25.5 \\
\hline Bank, post offices & 47 & 4.1 \\
\hline Economy & 71 & 6.2 \\
\hline Agriculture, forestry, etc. & 26 & 2.3 \\
\hline Police, army, etc. & 28 & 2.4 \\
\hline Other & 208 & 18.0 \\
\hline
\end{tabular}




\section{Table 2}

Percentages of participants that consider the measures and guidelines important, unimportant or are not sure about their importance.

\begin{tabular}{|c|c|c|c|c|}
\hline Guidelines & $\begin{array}{l}\text { Important } \\
(\%)\end{array}$ & $\begin{array}{l}\text { Unimportan } \\
\mathrm{t}(\%)\end{array}$ & $\begin{array}{l}\text { Not sure } \\
(\%)\end{array}$ & Total N \\
\hline \multicolumn{5}{|l|}{ Avoidance } \\
\hline Self-isolation in case of COVID-19 related symptoms & 96.5 & 2.0 & 1.4 & 980 \\
\hline Self-isolation in case of contact with a person with COVID-19 & 94.6 & 2.6 & 2.9 & 980 \\
\hline Avoiding touching the face and mask with unwashed hands & 94.2 & 3.1 & 2.7 & 970 \\
\hline Keeping a safe interpersonal distance & 94.0 & 3.5 & 2.5 & 972 \\
\hline Avoiding unnecessary contact with surfaces (handles, fences) outside of home & 91.0 & 6.3 & 2.8 & 973 \\
\hline Self-isolation after returning from abroad (after 13 March 2020) & 85.4 & 8.1 & 6.5 & 979 \\
\hline Having shopping done by a less vulnerable person & 59.8 & 33.7 & 6.5 & 975 \\
\hline Respecting the set shopping hour restrictions & 53.4 & 37.6 & 9.1 & 980 \\
\hline Use of alternative (online) shopping methods & 41.5 & 44.1 & 14.4 & 978 \\
\hline Emptying the mailbox a day or two after receipt & 26.6 & 59.5 & 13.9 & 973 \\
\hline \multicolumn{5}{|l|}{ Hygiene } \\
\hline Adherence to the rules of cough hygiene & 99.6 & 0.2 & 0.2 & 980 \\
\hline Regular and thorough hand washing/disinfection & 99.0 & 0.4 & 0.6 & 979 \\
\hline Regular indoor ventilation & 93.4 & 4.3 & 2.3 & 971 \\
\hline $\begin{array}{l}\text { Discarding potentially infected objects (handkerchiefs, masks, gloves) into a special } \\
\text { container }\end{array}$ & 72.5 & 18.6 & 8.9 & 979 \\
\hline Disinfection of areas in the house, shared by several households & 70.8 & 20.2 & 9.0 & 975 \\
\hline Regular replacement of disposable gloves and/or regular disinfection of reusable gloves & 65.6 & 26.6 & 7.8 & 971 \\
\hline Disinfection of surfaces (handles, light switches, counters) at home & 51.9 & 38.3 & 9.7 & 978 \\
\hline Wiping/disinfection of packaging from the store & 41.5 & 44.1 & 14.4 & 978 \\
\hline Separate use of clothing at home and outside & 43.0 & 44.0 & 13.1 & 980 \\
\hline \multicolumn{5}{|l|}{ Mask/gloves } \\
\hline Use of a protective mask in enclosed spaces outside of home & 74.5 & 16.6 & 9.0 & 972 \\
\hline Use of a scarf/shawl (instead of a protective mask) in enclosed spaces outside of home & 48.9 & 37.0 & 14.0 & 969 \\
\hline Use of gloves in enclosed spaces outside of home & 35.9 & 53.9 & 10.2 & 969 \\
\hline Use of a scarf/shawl (instead of a protective mask) outdoors & 10.1 & 82.5 & 7.4 & 970 \\
\hline Use of a protective mask outdoors & 7.1 & 87.1 & 5.8 & 972 \\
\hline Use of gloves outdoors & 6.9 & 88.7 & 4.4 & 969 \\
\hline
\end{tabular}

Note. Guidelines perceived as important by more than $90 \%$ of participants are bolded. 


\section{Table 3}

Effect of the level of participants' concern of infection with COVID-19 and infecting loved ones on (a) perceived importance and $(b)$ frequency of implementation of mitigation measures and health guidelines.

\begin{tabular}{|c|c|c|c|c|}
\hline \multirow[t]{2}{*}{ Guidelines } & \multicolumn{2}{|c|}{ Concern of infection } & \multicolumn{2}{|c|}{ Concern of infecting others } \\
\hline & $\mathrm{a}$ & $\mathrm{b}$ & $\mathrm{a}$ & $\mathrm{b}$ \\
\hline \multicolumn{5}{|l|}{ Avoidance } \\
\hline Limitation of physical contact to household members only & $<0.001$ & 0.006 & $<0.001$ & 0.056 \\
\hline Avoiding touching the face and mask with unwashed hands & 0.047 & $<0.001$ & 0.006 & 0.037 \\
\hline Avoiding unnecessary contact with surfaces (handles, fences) outside of home & 0.001 & $<0.001$ & 0.009 & 0.001 \\
\hline Keeping a safe interpersonal distance & $<0.001$ & $<0.001$ & $<0.001$ & $<0.001$ \\
\hline Respecting the set shopping hour restrictions & $<0.001$ & 0.080 & $<0.001$ & 0.001 \\
\hline Avoidance of enclosed spaces outside of home & $<0.001$ & $<0.001$ & $<0.001$ & $<0.001$ \\
\hline Use of alternative (online) shopping methods & 0.001 & 0.125 & 0.197 & 0.027 \\
\hline Emptying the mailbox a day or two after receipt & $<0.001$ & $<0.001$ & $<0.001$ & $<0.001$ \\
\hline Having shopping done by a less vulnerable person & 0.021 & $<0.001$ & 0.044 & 0.021 \\
\hline Self-isolation in case of COVID-19 related symptoms & $<0.001$ & - & 0.010 & - \\
\hline Self-isolation in case of contact with a person with COVID-19 & $<0.001$ & - & $<0.001$ & - \\
\hline Self-isolation after returning from abroad (after 13 March 2020) & $<0.001$ & - & 0.056 & - \\
\hline \multicolumn{5}{|l|}{ Hygiene } \\
\hline Regular and thorough hand washing/disinfection & 0.830 & $<0.001$ & 0.217 & 0.001 \\
\hline Adherence to the rules of cough hygiene & 0.408 & 0.972 & 0.381 & 0.556 \\
\hline Regular replacement of disposable masks and/or regular disinfection of reusable masks & $<0.001$ & $<0.001$ & $<0.001$ & $<0.001$ \\
\hline $\begin{array}{l}\text { Regular replacement of disposable gloves and/or regular disinfection of reusable } \\
\text { gloves }\end{array}$ & $<0.001$ & $<0.001$ & 0.012 & $<0.001$ \\
\hline Regular indoor ventilation & 0.085 & 0.422 & 0.971 & 0.489 \\
\hline $\begin{array}{l}\text { Discarding potentially infected objects (handkerchiefs, masks, gloves) into a special } \\
\text { container }\end{array}$ & $<0.001$ & $<0.001$ & $<0.001$ & $<0.001$ \\
\hline Disinfection of surfaces (handles, light switches, counters) at home & $<0.001$ & $<0.001$ & $<0.001$ & $<0.001$ \\
\hline Disinfection of areas in the house, shared by several households & $<0.001$ & $<0.001$ & 0.006 & $<0.001$ \\
\hline Wiping/disinfection of packaging from the store & $<0.001$ & $<0.001$ & $<0.001$ & $<0.001$ \\
\hline Separate use of clothing at home and outside & $<0.001$ & $<0.001$ & $<0.001$ & $<0.001$ \\
\hline \multicolumn{5}{|l|}{ Mask/gloves } \\
\hline Use of a protective mask in enclosed spaces outside of home & $<0.001$ & $<0.001$ & $<0.001$ & $<0.001$ \\
\hline Use of gloves in enclosed spaces outside of home & $<0.001$ & $<0.001$ & 0.002 & $<0.001$ \\
\hline Use of a protective mask outdoors & $<0.001$ & $<0.001$ & 0.006 & $<0.001$ \\
\hline Use of a scarf/shawl (instead of a protective mask) in enclosed spaces outside of home & 0.002 & 0.953 & 0.029 & 0.334 \\
\hline Use of a scarf/shawl (instead of a protective mask) outdoors & $<0.001$ & $<0.001$ & 0.002 & $<0.001$ \\
\hline Use of gloves outdoors & $<0.001$ & $<0.001$ & $<0.001$ & $<0.001$ \\
\hline
\end{tabular}




\section{Table 4}

Effects of gender, age, education, settlement size, employment field and type, household type, own medical problems, and age and health status of the participants' loved ones on their perception of the importance of selected guidelines.

\begin{tabular}{|c|c|c|c|c|c|c|c|c|c|}
\hline Guidelines & Gender & Age class & Education & $\begin{array}{l}\text { Settlement } \\
\text { size }\end{array}$ & $\begin{array}{c}\text { Employment } \\
\text { type }\end{array}$ & $\begin{array}{l}\text { Employment } \\
\text { field }\end{array}$ & $\begin{array}{c}\text { Household } \\
\text { type }\end{array}$ & $\begin{array}{c}\text { Medical } \\
\text { problems }\end{array}$ & $\begin{array}{l}\text { Health status / } \\
\text { age of others }\end{array}$ \\
\hline \multicolumn{10}{|c|}{$e^{2}$} \\
\hline Limitation of physical contact to household members only & 0.087 & 0.317 & 0.252 & 0.102 & 0.788 & 0.834 & 0.310 & 0.604 & 0.603 \\
\hline Avoiding touching the face and mask with unwashed hands & 0.643 & 0.248 & 0.147 & 0.131 & 0.200 & 0.172 & 0.113 & 0.566 & 0.956 \\
\hline $\begin{array}{l}\text { Avoiding unnecessary contact with surfaces (handles, fences) outside of } \\
\text { home }\end{array}$ & 0.284 & 0.092 & 0.521 & 0.160 & 0.694 & 0.288 & 0.289 & 0.580 & 0.496 \\
\hline Keeping a safe interpersonal distance & 0.879 & 0.085 & 0.380 & 0.111 & 0.728 & 0.372 & 0.085 & 0.616 & 0.878 \\
\hline Respecting the set shopping hour restrictions & 0.162 & 0.050 & 0.123 & 0.589 & 0.552 & 0.678 & 0.655 & 0.102 & 0.056 \\
\hline Avoidance of enclosed spaces outside of home & $<0.001$ & 0.396 & 0.794 & 0.408 & 0.696 & 0.496 & 0.725 & 0.397 & 0.353 \\
\hline Use of alternative (online) shopping methods & 0.179 & 0.448 & 0.054 & 0.325 & 0.397 & 0.097 & 0.469 & 0.408 & 0.294 \\
\hline Emptying the mailbox a day or two after receipt & 0.101 & 0.004 & 0.051 & 0.425 & 0.252 & 0.621 & 0.455 & 0.644 & 0.044 \\
\hline Having shopping done by a less vulnerable person & 0.005 & $<0.001$ & 0.002 & 0.174 & $<0.001$ & 0.608 & 0.149 & 0.739 & 0.250 \\
\hline Self-isolation in case of COVID-19 related symptoms & 0.812 & 0.053 & 0.003 & 0.294 & 0.080 & 0.114 & 0.301 & 0.601 & 0.965 \\
\hline Self-isolation in case of contact with a person with COVID-19 & 0.406 & 0.600 & 0.916 & 0.316 & 0.867 & 0.031 & 0.141 & 0.248 & 0.690 \\
\hline Self-isolation after returning from abroad (after 13 March 2020) & 0.102 & 0.015 & 0.608 & 0.225 & 0.567 & 0.500 & 0.171 & 0.259 & 0.661 \\
\hline \multicolumn{10}{|l|}{ Hygiene } \\
\hline Adherence to the rules of cough hygiene & 0.098 & 0.758 & 0.908 & 0.588 & 0.632 & 0.974 & 0.629 & 0.803 & 0.956 \\
\hline Regular and thorough hand washing/disinfection & 0.554 & 0.565 & 0.958 & 0.670 & 0.981 & 0.831 & 0.121 & 0.509 & 0.431 \\
\hline $\begin{array}{l}\text { Discarding potentially infected objects (handkerchiefs, masks, gloves) into a } \\
\text { special container }\end{array}$ & 0.017 & 0.021 & 0.504 & 0.930 & 0.871 & 0.425 & 0.684 & 0.684 & 0.068 \\
\hline Disinfection of surfaces (handles, light switches, counters) at home & $<0.001$ & $<0.001$ & 0.044 & 0.395 & 0.051 & 0.340 & 0.026 & 0.208 & 0.219 \\
\hline Disinfection of areas in the house, shared by several households & 0.005 & 0.003 & 0.849 & 0.097 & 0.658 & 0.913 & 0.704 & 0.278 & 0.966 \\
\hline Wiping/disinfection of packaging from the store & 0.086 & $<0.001$ & 0.101 & 0.091 & $<0.001$ & 0.835 & 0.087 & 0.053 & 0.007 \\
\hline Separate use of clothing at home and outside & 0.045 & 0.005 & 0.128 & 0.280 & 0.102 & 0.935 & 0.416 & 0.514 & 0.305 \\
\hline Regular indoor ventilation & 0.002 & 0.576 & 0.373 & 0.665 & 0.018 & 0.001 & 0.230 & 0.009 & 0.320 \\
\hline $\begin{array}{l}\text { Regular replacement of disposable masks and/or regular disinfection of } \\
\text { reusable masks }\end{array}$ & 0.008 & 0.181 & 0.831 & 0.050 & 0.484 & 0.218 & 0.275 & 0.368 & 0.486 \\
\hline $\begin{array}{l}\text { Regular replacement of disposable gloves and/or regular disinfection of } \\
\text { reusable gloves }\end{array}$ & 0.032 & 0.128 & 0.201 & 0.629 & 0.574 & 0.125 & 0.178 & 0.093 & 0.032 \\
\hline \multicolumn{10}{|l|}{ Mask/gloves } \\
\hline Use of a protective mask in enclosed spaces outside of home & 0.252 & 0.001 & 0.144 & 0.100 & 0.170 & 0.059 & 0.867 & 0.053 & 0.882 \\
\hline Use of a protective mask outdoors & 0.458 & 0.013 & 0.160 & 0.036 & 0.002 & 0.870 & 0.246 & 0.219 & 0.006 \\
\hline $\begin{array}{l}\text { Use of a scarf/shawl (instead of a protective mask) in enclosed spaces } \\
\text { outside of home }\end{array}$ & 0.118 & 0.293 & 0.037 & 0.377 & 0.541 & 0.613 & 0.069 & 0.648 & 0.759 \\
\hline Use of a scarf/shawl (instead of a protective mask) outdoors & 0.076 & $<0.001$ & 0.005 & 0.807 & 0.004 & 0.751 & 0.023 & 0.520 & 0.131 \\
\hline Use of gloves in enclosed spaces outside of home & 0.880 & $<0.001$ & 0.001 & 0.073 & 0.002 & 0.037 & 0.363 & 0.488 & 0.010 \\
\hline Use of gloves outdoors & 0.445 & $<0.001$ & 0.076 & $\mathbf{0 . 0 3 3}$ & $<0.001$ & 0.683 & 0.063 & 0.317 & 0.005 \\
\hline
\end{tabular}

Note. Significant effects $(\mathrm{p}<0.05)$ are bolded. 
Table 5

Percentages of participants by frequency of guideline implementation.

\begin{tabular}{|c|c|c|c|c|c|c|}
\hline Guidelines & $\begin{array}{c}\text { Never } \\
(\%)\end{array}$ & $\begin{array}{c}\text { Rarely } \\
(\%)\end{array}$ & $\begin{array}{c}\text { Sometimes } \\
(\%)\end{array}$ & $\begin{array}{c}\text { Often } \\
(\%)\end{array}$ & $\begin{array}{c}\text { Always } \\
(\%)\end{array}$ & $\begin{array}{c}\text { Total } \\
\mathrm{N}\end{array}$ \\
\hline \multicolumn{7}{|l|}{ Avoidance } \\
\hline Respecting the set shopping hour restrictions & 2.6 & 1 & 1.7 & 6.9 & 87.7 & 869 \\
\hline Keeping a safe interpersonal distance & 0.3 & 1.1 & 3.1 & 29 & 66.5 & 937 \\
\hline Avoiding touching the face and mask with unwashed hands & 2.3 & 3.5 & 6.3 & 30.8 & 57.1 & 932 \\
\hline Avoiding unnecessary contact with surfaces (handles, fences) outside of home & 1.9 & 2.3 & 7.2 & 33.3 & 55.3 & 937 \\
\hline Limitation of physical contact to household members only & 9.2 & 3.4 & 4.5 & 28.5 & 54.5 & 892 \\
\hline Avoidance of enclosed spaces outside of home & 3 & 4.4 & 10 & 47.4 & 35.1 & 922 \\
\hline Having shopping done by a less vulnerable person & 67.6 & 4.3 & 7.2 & 7.5 & 13.3 & 623 \\
\hline Emptying the mailbox a day or two after receipt & 47.2 & 14.6 & 12.2 & 12.9 & 13.1 & 924 \\
\hline Use of alternative (online) shopping methods & 15.7 & 16.1 & 28.8 & 26.5 & 12.9 & 928 \\
\hline \multicolumn{7}{|l|}{ Hygiene } \\
\hline Adherence to the rules of cough hygiene & 0.7 & 0.4 & 1.1 & 11.7 & 86.1 & 940 \\
\hline Regular and thorough hand washing/disinfection & 0.3 & 0.6 & 2.3 & 20.7 & 76.1 & 957 \\
\hline Regular indoor ventilation & 1.1 & 1 & 4.1 & 32.6 & 61.3 & 943 \\
\hline $\begin{array}{l}\text { Regular replacement of disposable gloves and/or regular disinfection of } \\
\text { reusable gloves }\end{array}$ & 18.8 & 5.1 & 6.9 & 16.2 & 52.9 & 865 \\
\hline $\begin{array}{l}\text { Regularly replacement of disposable masks and/or regular disinfection of } \\
\text { reusable masks }\end{array}$ & 11.8 & 6 & 8.3 & 21.6 & 52.3 & 883 \\
\hline $\begin{array}{l}\text { Discarding potentially infected objects (handkerchiefs, masks, gloves) into a } \\
\text { special container }\end{array}$ & 20.4 & 10.8 & 13.8 & 14.4 & 40.5 & 925 \\
\hline Disinfection of areas in the house, shared by several households & 23.2 & 8.9 & 10.5 & 25.1 & 32.3 & 582 \\
\hline Wiping/disinfection of packaging from the store & 37.8 & 13 & 13.6 & 12 & 23.6 & 943 \\
\hline Disinfection of surfaces (handles, light switches, counters) at home & 24.5 & 17.1 & 20.2 & 21.6 & 16.6 & 947 \\
\hline Separate use of clothing at home and outside & 34.7 & 10.8 & 10.8 & 5.6 & 28 & 942 \\
\hline \multicolumn{7}{|l|}{ Mask/gloves } \\
\hline Use of a protective mask in enclosed spaces outside of home & 6.8 & 3.2 & 4.4 & 18 & 67.6 & 911 \\
\hline Use of gloves in enclosed spaces outside of home & 19.3 & 14.1 & 15.3 & 18.3 & 33.3 & 914 \\
\hline $\begin{array}{l}\text { Use a scarf/shawl (instead of a protective mask) in enclosed spaces outside of } \\
\text { home }\end{array}$ & 51.5 & 10.5 & 11 & 9.2 & 17.9 & 861 \\
\hline Use of gloves outdoors & 79.1 & 10.5 & 4.6 & 1.6 & 4.2 & 932 \\
\hline Use of a protective mask outdoors & 74.7 & 13 & 6 & 2.3 & 4.1 & 932 \\
\hline Use a scarf/shawl (instead of a protective mask) outdoors & 81.4 & 9.5 & 4.4 & 2.1 & 2.6 & 893 \\
\hline
\end{tabular}

Note. Guidelines always implemented by more than $50 \%$ of participants are bolded. 


\section{Table 6}

Effects of gender, age class, education, settlement size, employment field and type, household type, own medical problems, and age and health status of the participants' loved ones on the frequency of guideline implementation.

\begin{tabular}{|c|c|c|c|c|c|c|c|c|c|}
\hline Guidelines & Gender & $\begin{array}{l}\text { Age } \\
\text { class }\end{array}$ & Education & $\begin{array}{l}\text { Settlement } \\
\text { size }\end{array}$ & $\begin{array}{c}\text { Employment } \\
\text { type }\end{array}$ & $\begin{array}{l}\text { Employment } \\
\text { field }\end{array}$ & $\begin{array}{c}\begin{array}{c}\text { Household } \\
\text { type }\end{array} \\
\end{array}$ & $\begin{array}{c}\text { Medical } \\
\text { problems }\end{array}$ & $\begin{array}{c}\text { Health of } \\
\text { others }\end{array}$ \\
\hline \multicolumn{10}{|l|}{ Avoidance } \\
\hline Limitation of physical contacts to household members only & 0.162 & 0.286 & $<0.001$ & 0.001 & 0.920 & 0.092 & 0.038 & 0.474 & 0.309 \\
\hline Avoiding touching the face and mask with unwashed hands & 0.037 & 0.003 & 0.124 & 0.719 & 0.178 & 0.229 & 0.486 & 0.830 & 0.489 \\
\hline $\begin{array}{l}\text { Avoiding unnecessary contact with surfaces (handles, fences) outside of } \\
\text { home }\end{array}$ & 0.031 & 0.103 & 0.090 & 0.184 & 0.258 & 0.703 & 0.072 & 0.684 & 0.417 \\
\hline Keeping a safe interpersonal distance & 0.158 & 0.002 & 0.136 & 0.748 & 0.115 & 0.602 & 0.714 & 0.879 & 0.142 \\
\hline Respecting the set shopping hour restrictions & 0.293 & 0.007 & 0.199 & 0.239 & 0.107 & 0.891 & 0.388 & 0.851 & 0.487 \\
\hline Avoidance of enclosed spaces outside of home & $<0.001$ & 0.138 & 0.507 & 0.481 & 0.039 & 0.494 & 0.020 & 0.694 & 0.075 \\
\hline Use of alternative (online) shopping methods & 0.510 & 0.105 & 0.267 & 0.335 & 0.104 & 0.157 & 0.026 & 0.564 & 0.371 \\
\hline Emptying the mailbox a day or two after receipt & 0.274 & $<0.001$ & 0.156 & 0.152 & 0.054 & 0.332 & 0.155 & 0.364 & 0.027 \\
\hline Having shopping done by a less vulnerable person & $<0.001$ & 0.072 & 0.252 & 0.150 & 0.016 & 0.199 & 0.041 & $<0.001$ & 0.544 \\
\hline \multicolumn{10}{|l|}{ Hygiene } \\
\hline Regular and thorough hand washing/disinfection & 0.035 & $<0.001$ & 0.117 & 0.816 & 0.021 & 0.055 & 0.098 & 0.863 & 0.588 \\
\hline Adherence to the rules of cough hygiene & 0.152 & 0.009 & 0.081 & 0.248 & 0.017 & 0.035 & 0.626 & 0.761 & 0.907 \\
\hline $\begin{array}{l}\text { Regular replacement of disposable masks and/or regular disinfection of } \\
\text { reusable masks }\end{array}$ & $<0.001$ & 0.086 & 0.056 & 0.061 & 0.163 & 0.141 & 0.304 & 0.963 & 0.121 \\
\hline $\begin{array}{l}\text { Regular replacement of disposable gloves and/or regular disinfection of } \\
\text { reusable gloves }\end{array}$ & 0.001 & 0.116 & 0.084 & 0.052 & 0.216 & 0.565 & 0.526 & 0.544 & 0.017 \\
\hline Regular indoor ventilation & $<0.001$ & 0.047 & 0.109 & 0.659 & 0.232 & 0.310 & 0.871 & 0.558 & 0.133 \\
\hline $\begin{array}{l}\text { Discarding potentially infected objects (handkerchiefs, masks, gloves) into a } \\
\text { special container }\end{array}$ & 0.021 & $<0.001$ & 0.170 & 0.103 & 0.001 & 0.037 & 0.886 & 0.338 & 0.228 \\
\hline Disinfection of surfaces (handles, switches, counters) at home & $<0.001$ & $<0.001$ & 0.004 & 0.732 & 0.001 & 0.082 & 0.673 & 0.099 & 0.014 \\
\hline Disinfection of areas in the house, shared by several households & 0.431 & $<0.001$ & 0.425 & 0.556 & 0.007 & 0.764 & 0.115 & 0.198 & 0.290 \\
\hline Wiping/disinfection of packaging from the store & 0.642 & $<0.001$ & 0.968 & 0.486 & 0.003 & 0.799 & 0.056 & 0.016 & 0.016 \\
\hline Separate use of clothing at home and outside & 0.029 & $<0.001$ & 0.742 & 0.659 & 0.236 & 0.240 & 0.537 & 0.369 & 0.254 \\
\hline \multicolumn{10}{|l|}{ Mask/gloves } \\
\hline Use of a protective mask in enclosed spaces outside of home & 0.007 & 0.173 & 0.278 & 0.069 & 0.086 & 0.261 & 0.132 & 0.717 & 0.673 \\
\hline Use of a protective mask outdoors & 0.703 & $<0.001$ & 0.092 & 0.227 & 0.029 & 0.971 & 0.111 & 0.130 & $<0.001$ \\
\hline $\begin{array}{l}\text { Use of a scarf/shawl (instead of a protective mask) in enclosed spaces outside } \\
\text { of home }\end{array}$ & 0.296 & 0.978 & 0.277 & 0.481 & 0.067 & 0.514 & 0.938 & 0.475 & 0.953 \\
\hline Use of a scarf/shawl (instead of a protective mask) outdoors & 0.472 & 0.001 & 0.087 & 0.078 & 0.003 & 0.048 & 0.110 & 0.006 & 0.058 \\
\hline Use of gloves in enclosed spaces outside of home & 0.060 & 0.007 & 0.007 & 0.036 & 0.007 & 0.058 & 0.867 & 0.235 & 0.003 \\
\hline Use of gloves outdoors & 0.349 & $<0.001$ & 0.040 & 0.041 & 0.017 & 0.697 & 0.670 & 0.509 & $<0.001$ \\
\hline
\end{tabular}


Table 7

The relation between type of contact with vulnerable individuals (people with chronic medical issues, weakened immune system or older than 65 years) during the lockdown and the participants' general frequency of guideline implementation. Participants chose between meeting vulnerable individuals with respecting health guidelines or without respecting health guidelines or having no contact with vulnerable individuals.

\begin{tabular}{|c|c|c|c|}
\hline Guidelines & $\begin{array}{c}\text { Chronic } \\
\text { medical issue }\end{array}$ & $\begin{array}{c}\text { Weakened } \\
\text { immune system }\end{array}$ & $\begin{array}{l}\text { Over } 65 \\
\text { years old }\end{array}$ \\
\hline \multicolumn{4}{|l|}{ Avoidance } \\
\hline Limitation of physical contacts to household members only & 0.008 & 0.018 & $<0.001$ \\
\hline Avoiding touching the face and mask with unwashed hands & 0.002 & 0.964 & 0.001 \\
\hline Avoiding unnecessary contact with surfaces (handles, fences) outside of home & 0.299 & 0.878 & 0.056 \\
\hline Keeping a safe interpersonal distance & 0.001 & 0.407 & 0.034 \\
\hline Respecting the set shopping hour restrictions & 0.039 & 0.055 & $<0.001$ \\
\hline Avoidance of enclosed spaces outside of home & 0.475 & 0.300 & 0.003 \\
\hline Use of alternative (online) shopping methods & 0.186 & 0.950 & 0.521 \\
\hline Emptying the mailbox a day or two after receipt & 0.001 & 0.231 & 0.003 \\
\hline Having shopping done by a less vulnerable person & 0.312 & 0.413 & 0.571 \\
\hline \multicolumn{4}{|l|}{ Hygiene } \\
\hline Regular and thorough hand washing/disinfection & 0.004 & 0.416 & $<0.001$ \\
\hline Adherence to the rules of cough hygiene & 0.085 & 0.423 & 0.003 \\
\hline Regular replacement of disposable masks and/or regular disinfection of reusable masks & 0.005 & 0.780 & 0.012 \\
\hline Regular replacement of disposable gloves and/or regular disinfection of reusable gloves & 0.097 & 0.374 & 0.120 \\
\hline Regular indoor ventilation & 0.009 & 0.144 & 0.309 \\
\hline $\begin{array}{l}\text { Discarding potentially infected objects (handkerchiefs, masks, gloves) into a special } \\
\text { container }\end{array}$ & 0.282 & 0.760 & 0.135 \\
\hline Disinfection of surfaces (handles, switches, counters) at home & 0.773 & 0.742 & 0.236 \\
\hline Disinfection of areas in the house, shared by several households & 0.307 & 0.796 & 0.186 \\
\hline Wiping/disinfection of packaging from the store & 0.188 & 0.848 & 0.446 \\
\hline Separate use of clothing at home and outside & 0.236 & 0.546 & 0.668 \\
\hline \multicolumn{4}{|l|}{ Mask/gloves } \\
\hline Use of a protective mask in enclosed spaces outside of home & 0.436 & 0.626 & 0.216 \\
\hline Use of a protective mask outdoors & 0.009 & 0.319 & 0.681 \\
\hline Use of a scarf/shawl (instead of a protective mask) in enclosed spaces outside of home & 0.022 & 0.043 & 0.266 \\
\hline Use of a scarf/shawl (instead of a protective mask) outdoors & 0.312 & 0.300 & 0.821 \\
\hline Use of gloves in enclosed spaces outside of home & 0.571 & 0.298 & 0.332 \\
\hline Use of gloves outdoors & 0.649 & 0.426 & 0.959 \\
\hline
\end{tabular}

8 Note. Significant effects $(\mathrm{p}<0.05)$ are bolded. 
Table 8

Significance levels of Kendall-tau correlations between personality dimensions (conscientiousness, neuroticism, openness, energy and agreeableness) and adherence to mitigation measures and health guidelines.

\begin{tabular}{|c|c|c|c|c|c|}
\hline Guidelines & Conscientiousness & Openness & Energy & Agreeableness & Neuroticism \\
\hline \multicolumn{6}{|l|}{ Avoidance } \\
\hline Limitation of physical contacts to household members only & $0.004^{+}$ & $0.004^{+}$ & 0.331 & 0.652 & 0.554 \\
\hline Avoiding touching the face and mask with unwashed hands & $0.007^{+}$ & $<0.001^{+}$ & $0.006^{+}$ & $0.031^{+}$ & $0.025^{+}$ \\
\hline $\begin{array}{l}\text { Avoiding unnecessary contact with surfaces (handles, fences) } \\
\text { outside of home }\end{array}$ & $<0.001^{+}$ & 0.122 & 0.453 & 0.071 & 0.131 \\
\hline Keeping a safe interpersonal distance & $<0.001^{+}$ & $0.004^{+}$ & $0.037^{+}$ & $0.027^{+}$ & 0.273 \\
\hline Respecting the set shopping hour restrictions & 0.057 & 0.372 & 0.091 & 0.552 & 0.149 \\
\hline Avoidance of enclosed spaces outside of home & 0.051 & 0.100 & 0.613 & 0.376 & 0.486 \\
\hline Use of alternative (online) shopping methods & 0.496 & 0.002 & 0.235 & 0.902 & 0.850 \\
\hline Emptying the mailbox a day or two after receipt & 0.080 & 0.822 & 0.993 & 0.889 & 0.949 \\
\hline Having shopping done by a less vulnerable person & 0.198 & 0.494 & $0.006^{-}$ & 0.251 & 0.078 \\
\hline \multicolumn{6}{|l|}{ Hygiene } \\
\hline Regular and thorough hand washing/disinfection & $0.011+$ & $<0.001^{+}$ & $0.002+$ & $0.013^{+}$ & $0.032^{+}$ \\
\hline Adherence to the rules of cough hygiene & 0.568 & $0.017^{+}$ & 0.127 & $0.004^{+}$ & $0.048^{+}$ \\
\hline $\begin{array}{l}\text { Regular replacement of disposable masks and/or regular } \\
\text { disinfection of reusable masks }\end{array}$ & 0.161 & 0.821 & 0.882 & 0.932 & 0.831 \\
\hline $\begin{array}{l}\text { Regular replacement of disposable gloves and/or regular } \\
\text { disinfection of reusable gloves }\end{array}$ & $0.019^{+}$ & 0.898 & 0.779 & 0.482 & 0.548 \\
\hline Regular indoor ventilation & 0.152 & 0.100 & $<0.001^{+}$ & 0.125 & 0.365 \\
\hline $\begin{array}{l}\text { Discarding potentially infected objects (handkerchiefs, masks, } \\
\text { gloves) into a special container }\end{array}$ & $0.040^{+}$ & $0.031^{+}$ & 0.274 & $0.018^{+}$ & $0.002^{+}$ \\
\hline Disinfection of surfaces (handles, switches, counters) at home & $0.008^{+}$ & 0.122 & $0.001^{+}$ & 0.228 & 0.490 \\
\hline Disinfection of areas in the house, shared by several households & $0.001^{+}$ & 0.060 & 0.336 & 0.789 & 0.353 \\
\hline Wiping/disinfection of packaging from the store & $<0.001^{+}$ & $0.007^{+}$ & 0.302 & 0.089 & 0.451 \\
\hline Separate use of clothing at home and outside & $0.003^{+}$ & 0.312 & 0.848 & 0.134 & 0.957 \\
\hline \multicolumn{6}{|l|}{ Mask/gloves } \\
\hline Use of a protective mask in enclosed spaces outside of home & $0.011^{+}$ & 0.601 & 0.960 & 0.385 & 0.754 \\
\hline Use of gloves in enclosed spaces outside of home & $0.002^{+}$ & 0.493 & 0.201 & 0.459 & 0.995 \\
\hline Use of a protective mask outdoors & $0.033^{+}$ & 0.843 & 0.884 & 0.233 & 0.523 \\
\hline $\begin{array}{l}\text { Use of a scarf/shawl (instead of a protective mask) in enclosed } \\
\text { spaces outside of home }\end{array}$ & $0.026^{-}$ & 0.534 & 0.456 & 0.197 & 0.443 \\
\hline Use of a scarf/shawl (instead of a protective mask) outdoors & 0.717 & 0.773 & 0.815 & 0.398 & 0.862 \\
\hline Use of gloves outdoors & 0.392 & 0.423 & 0.655 & 0.189 & 0.989 \\
\hline
\end{tabular}

